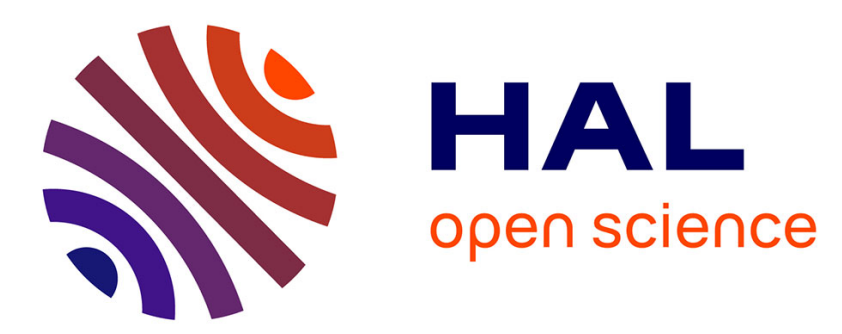

\title{
A multifaceted look at time of admission and its impact on case-fatality among a cohort of ischemic stroke patients
}

Uzor C Ogbu, Gert P Westert, Laurentius Cj Slobbe, Karien Stronks, Onyebuchi A Arah

\section{To cite this version:}

Uzor C Ogbu, Gert P Westert, Laurentius Cj Slobbe, Karien Stronks, Onyebuchi A Arah. A multifaceted look at time of admission and its impact on case-fatality among a cohort of ischemic stroke patients. Journal of Neurology, Neurosurgery and Psychiatry, 2010, 82 (1), pp.8. 10.1136/jnnp.2009.202176. hal-00560317

\section{HAL Id: hal-00560317 https://hal.science/hal-00560317}

Submitted on 28 Jan 2011

HAL is a multi-disciplinary open access archive for the deposit and dissemination of scientific research documents, whether they are published or not. The documents may come from teaching and research institutions in France or abroad, or from public or private research centers.
L'archive ouverte pluridisciplinaire HAL, est destinée au dépôt et à la diffusion de documents scientifiques de niveau recherche, publiés ou non, émanant des établissements d'enseignement et de recherche français ou étrangers, des laboratoires publics ou privés. 


\section{A multifaceted look at time of admission and its impact on case- fatality among a cohort of ischemic stroke patients}

Uzor C. Ogbu, $\mathrm{MD}^{1,2}$; Gert P. Westert, $\mathrm{PhD}^{2,3}$; Laurentius C.J. Slobbe, $\mathrm{MSc}^{2}$, Karien Stronks, $\mathrm{PhD}^{1}$; Onyebuchi A. Arah, $\mathrm{PhD}^{1,4}$

1. Department of Social Medicine, Academic Medical Center, University of Amsterdam, Amsterdam, Netherlands

2. Center for Prevention and Health Services Research, National Institute of Public Health and the Environment (RIVM), Bilthoven, Netherlands

3. Center for Transformation of Care and Welfare, Faculty of Social and Behavioral Sciences, Tilburg University, Tilburg, Netherlands

4. Department of Epidemiology, School of Public Health, University of California, Los Angeles (UCLA), 650 Charles E. Young Drive South, Los Angeles, CA 90095-1772, United States.

Corresponding author: Uzor C. Ogbu

J2 - 224, Department of Social Medicine, Academic Medical Center, University of Amsterdam, P.O. Box 22660, 1100DD Amsterdam, Netherlands E-mail: u.c.ogbu@amc.uva.nl Phone number: +31205664511

Fax: +31206972316

\section{Word Count: 3112}

Key words: acute stroke, quality of care, outcomes research, 


\begin{abstract}
Purpose: Off-hours admissions have been associated with an increased risk of poor outcomes but results have been inconsistent, possibly due to different measures of off-hours care used. We examined, using a single condition and increasingly refined definitions of time of admission, the effect of off-hours admissions on seven-day stroke case-fatality
\end{abstract}

Methods: We studied a retrospective cohort of 82,219 ischemic stroke admissions to 115 Dutch hospitals between 2000 and 2004. Data were from the Dutch Medical Register and analyzed using multivariable multilevel logistic regression. We adjusted for variables such as age, gender, CharlsonDeyo comorbidity score, urgency of admission, hospital teaching status and specialty of attending physician.

Results: After adjustment, we observed higher seven-day fatality risk for weekend admissions when compared to weekday admissions (odds ratio [OR] 1.27; 95\% Confidence interval [CI], 1.20 - 1.34). Sunday displayed the highest risk of fatality (OR 1.31; 95\% CI $1.20-1.44$ ). With the Monday dayshift as a reference, the fatality odds were increased during the Sunday and Saturday day-shifts, the evening-shifts on Sunday and Monday, and during all night-shifts. The night-shift OR's ranged from 1.94 (95\% CI $1.56-2.41)$, to 2.14 (95\% CI $1.74-2.63)$. When compared to admission at 8:00 AM we observed increased fatality odds from midnight until 7:00 AM and decreased fatality odds from 2:00 PM until 6:00 PM.

Conclusions: Weekends represent a period of increased fatality risk for ischemic stroke patients in the Netherlands. However, this increased risk appears to represent an exacerbation of an underlying nighttime risk present during the weekdays. 


\section{INTRODUCTION}

Studies have observed the increased fatality risk during the weekend, dubbed the 'weekend effect', and the increased risk at nighttime for both in-patients and new admissions.[1-11] The association extends beyond an increased fatality risk, to include increased risk of complications,[12] treatment delays,[13] and restricted availability of some procedures.[5] Outcomes for a number of conditions, such as stroke, pulmonary embolism, hip fractures and upper gastro-intestinal hemorrhage have shown this trend.[2;4;8;9;14-16] However, the association has not been consistently observed. In some studies where an association between case-fatality and time of admission was not observed, methodological bias, or specific interventions or protocols were cited as possible explanations. In addition, the definition of off-hours has varied from looking at weekend, defined as starting from the close of work on Friday[2;15] or starting at midnight on Friday, $[4 ; 8 ; 9 ; 14 ; 16]$ to including the day, or hour of admission.[6] These broad and fragmented pictures may have masked variation in fatality risk occurring during the off-hours.

Studies of the effect of off-hours admissions specific to stroke follow the pattern described above. Hasegawa et al[4] found weekday admission to be a negative predictor of case-fatality among stroke patients; Saposnik et al[8] observed higher risk adjusted case-fatality for patients admitted during the weekend. Luyt et al[17] observed no association between off-hours admissions and casefatality among stroke patients admitted to the ICU. Albright et al[18] observed a no association between weekend admission and case-fatality in two comprehensive stroke centers.

In a graduated fashion, using increasingly refined definitions of time of admission, extending from the calendar definition of weekends and weekdays to the day-, shift- and hour-of-admission, we modeled the association between time of admission and seven-day case-fatality among ischemic stroke patients admitted to all categories of hospitals in the Netherlands. 


\section{METHODS}

\section{Setting}

This is a retrospective cohort study. We obtained data from the Dutch Medical Register (LMR) through the Central Bureau of Statistics, Netherlands (CBS), which among other activities links these hospital data to other data sources in the Netherlands such as the population and mortality registers.[2;19;20] The LMR, collected since 1964, maintained by Prismant, Netherlands, contains over $99 \%$ of hospital admissions in the Netherlands. The quality of the data and linkage are ensured by Prismant and CBS.[19] The data are coded using International Classification of Disease, Ninth Revision, Clinical Modification (ICD-9 CM) standards. Using data from $1^{\text {st }}$ January 2000 through $31^{\text {st }}$ December 2004, we identified all patients with a discharge diagnosis of ischemic stroke (ICD-9 CM codes 433,434 and 436).[21] We excluded admissions for patients younger than 45 years and those that could not be definitively identified in the population register. Admissions with missing data were excluded and patients transferred between hospitals noted.

\section{Outcome}

The primary outcome was seven-day case-fatality, defined as a death occurring up to seven days from the day of admission, counting the day of admission as day one. The linkage with the mortality register allowed us to identify deaths occurring outside the hospital. Stroke is an acute condition with a high short-term case-fatality, using seven-day case-fatality seems appropriate to capture the association between time-of-admission and case-fatality.

\section{Time of admission}

We used five increasingly refined definitions of time of admission: weekday/weekend, day-ofadmission, shift-of-admission, day-and-shift of admission, and hour-of-admission. In our analysis, we took into account ten holidays celebrated in the Netherlands, characterized by working hours/shifts similar those used during the weekend. 
In the weekday/weekend categorization, weekends were defined as starting at midnight Friday and ending at 11:59 PM Sunday. Holidays were classified as weekends. All other admissions were considered weekday admissions. Weekday admissions were used as the reference category.

The day-of-admission was based on calendar definition of days, starting at midnight and ending 11:59 PM of each day. Holidays were coded on the day of the week they fell on. Monday admissions were used as the reference category.

Shift-of-admission was based on the regular working hours of physicians and consisted of three shifts on weekdays, and two on weekends. Accordingly, this resulted in five categories: weekday day-shift (Monday to Friday 8:00 AM to 4:59 PM); weekday evening-shift (Monday to Friday 5:00 PM to 10:59 PM); weekday night-shifts (Monday to Thursday 11:00 PM to 7:59 AM and Friday 11:00 PM to Saturday 7:59 AM); weekend day-shift (Saturday and Sunday 8:00 AM to 7:59 PM); and weekend night-shift (8:00 PM Saturday to 7:59 AM Sunday, and 8:00 PM Sunday to 7:59 AM Monday).

The weekday day-shift was the reference category. In recognition of the uneven hours in each shift we also carried out an analysis in which the days were divided into three eight-hour shifts (8:00 AM to 3:59 PM; 4:00 PM to 11:59 PM; midnight to 7:59 AM).

The day-and-shift of admission was defined by applying the definition of shift-of-admission to each day of the week. Holidays were included as separate category. This resulted in twenty-one categories, three each Monday to Friday (day, evening and night) and two each for Saturday, Sunday and holidays (day and night). The Monday day-shift was used as the reference category.

The hour-of-admission was based on the specific hour the patient presented in the hospital thus yielding twenty-four categories; 8:00 AM was used as the reference category.

\section{Covariates}

Based on the time of admission and stroke case-fatality literature, we included variables expected to influence the outcome or association between time of admission and seven-day case-fatality. These variables included age on admission, sex, socioeconomic status, type of insurance, ethnicity, urgency, 
previous stroke, Charlson-Deyo comorbidity score, attending physician specialty, year of admission, hospital teaching status, and hospital location.

Age on admission was used as a continuous variable. Socioeconomic status was based on ranked postal code income data. Insurance was either public or private, and serves as a more specific proxy for socioeconomic status. Ethnicity was defined by country of birth and divided into three groups, namely ethnic Dutch or other westerners, Turks or Moroccans, and Surinamese, Antilleans, or other non-westerners.[22] We suspected that ethnicity might have an influence on stroke fatality as has been seen in other conditions.[23] Urgency of admissions was an assessment in the hospital record, defined as those admissions that were not planned but could not be delayed because care was required. Urgency of admission is a standard variable in the LMR that gives an indication of the severity at presentation; it has been used in the estimation of the hospital standardized mortality ratio in the Netherlands.[24] Previous strokes were ascertained by looking back six years from the start of the study, until January 1, 1994. Patients admitted more than once in the study period was considered as having had a previous stroke during their second and/or subsequent admission(s). We estimated the Charlson-Deyo score in the same manner as that used in validation study among a cohort of ischemic stroke patients.[25] The score was categorized as 0,1 or $>1$. Attending physician specialty, representing the specialist in-charge of the case, consisted of two groups defined as neurologist/neurosurgeon, or other specialty. We used the year of admission to capture advances in treatment protocols or treatments themselves.

At the hospital level we included hospital teaching status (academic, top clinical and general), hospital location (rural or urban). Top clinical hospitals were general hospitals accredited for residency training. The hospital location was defined, by the degree of urbanization using its address, as follows: less than 500 addresses per $\mathrm{km}^{2}$ was classified as rural, from 500 to 1000 addresses as urban grade 1 , from 1000 to 1500 addresses as urban grade 2 , from 1500 to 2500 addresses as urban grade 3 , and greater than 2500 addresses per $\mathrm{km}^{2}$ as urban grade 4 . 


\section{Statistical analysis}

We carried out a descriptive analysis of our patient population separating them based on the weekend/weekday categorization of time of admission.

We modeled the association between time of admission and seven-day case-fatality using multivariable multilevel logistic regression to account for the clustering of outcomes. We built the model in stages for each definition of time of admission. We started with an unadjusted model and the progressed to one containing all covariates with the exception of attending physician. We only added this variable later as we thought that the attending physician might serve as an explanatory variable as opposed to being a confounder. We then included interactions between the time of admission, and each of hospital type, Charlson-Deyo comorbidity score, urgency of admission and attending physician to test if the association between time of admission and case-fatality differed by levels of these covariates.Significant interactions, identified using the likelihood ratio test, were included in a single model. For the day-and-shift of admission and hour-of-admission categorizations, we omitted the test of interactions due to the large number of categories involved and separately included the variables weekend admission, and day of admission. We also carried out stratified analysis modeling the hour-of-admission stratified by weekend and weekday admissions because of the previously highlighted differences between work patterns.

As a sensitivity analysis, we excluded all patients transferred between hospitals and repeated our analysis. This removes the potential bias in the case-fatality rates if more severe patients were transferred to more advanced hospitals.

Regression results were displayed as odds ratios (OR) and 95\% confidence intervals (CI). The variation between hospitals is expressed as the proportional change in variance (PCV), and intraclass correlation coefficient (ICC). All analyses were carried out using the xtlogit command in STATA Version 9.2 (StataCorp, College Station, TX). 


\section{RESULTS}

We identified 89,447 ischemic stroke admissions to 115 Dutch hospitals from 2000 through 2004 . We excluded 4118 admissions because the individuals were not traceable in the dataset, 2998 were for individuals under the age of 45 and 112 had missing values in one the variables included in the model ( 2 for ethnicity, 85 for type of insurance and 25 for the postcode based socioeconomic status). These exclusions resulted in a study population of 82,219 , including 21,599 admissions noted as referrals.

Table 1 displays a description of the characteristics of the patients included in the study. The mean age was 73 years. The majority of admissions were to top clinical hospitals and occurred during the day time.

\begin{tabular}{|c|c|c|c|}
\hline Characteristics & $\begin{array}{c}\text { All } \\
\text { admissions } \\
(\mathrm{N}=82219) \\
\text { No. }(\%)\end{array}$ & $\begin{array}{c}\text { Weekday } \\
\text { admissions } \\
(\mathrm{n}=63072) \\
\text { No. }(\%)\end{array}$ & 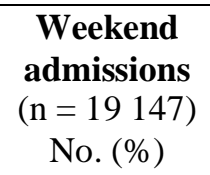 \\
\hline $\begin{array}{l}\text { Age, mean (SD), }{ }^{*} \\
\text { Hex }^{*}\end{array}$ & $73.0(11.1)$ & $72.9(11.0)$ & $73.5(11.1)$ \\
\hline Male & $42866(52.1)$ & $33101(52.5)$ & $9765(51.0)$ \\
\hline Female & $39353(47.9)$ & $29971(47.5)$ & $9382(49.0)$ \\
\hline \multicolumn{4}{|l|}{ Ethnicity } \\
\hline Dutch and other westerners & $80371(97.8)$ & $61669(97.8)$ & $18702(97.7)$ \\
\hline Turkish or Moroccan & $392(0.5)$ & $305(0.5)$ & $87(0.5)$ \\
\hline $\begin{array}{l}\text { Netherlands Antilles, Suriname and } \\
\text { other non-westerners }\end{array}$ & $1456(1.8)$ & $1098(1.7)$ & $358(1.9)$ \\
\hline \multicolumn{4}{|l|}{ Attending Physician* } \\
\hline Neurologist/Neurosurgeon & $71646(87.1)$ & $54007(85.6)$ & $17639(92.1)$ \\
\hline Other Physician & $10573(12.9)$ & $9065(14.4)$ & $1508(12.9)$ \\
\hline \multicolumn{4}{|l|}{ Insurance $^{*}$} \\
\hline Public & $60934(74.1)$ & $46564(73.8)$ & $14370(74.1)$ \\
\hline Private & $21285(25.9)$ & $16508(26.2)$ & $19147(25.9)$ \\
\hline \multicolumn{4}{|l|}{ Charlson-Deyo comorbidity score ${ }^{*}$} \\
\hline 0 & $73543(89.4)$ & $56349(89.3)$ & $17194(89.8)$ \\
\hline 1 & $4778(5.8)$ & $3778(6.0)$ & $1000(5.2)$ \\
\hline$\geq 2$ & $3898(4.7)$ & $2945(4.7)$ & $953(5.0)$ \\
\hline \multicolumn{4}{|l|}{ Urgency of Admission* } \\
\hline Non-urgent & $17959(21.8)$ & $16068(25.5)$ & $1891(9.9)$ \\
\hline Urgent & $64620(78.2)$ & $47004(74.1)$ & $17256(90.1)$ \\
\hline \multicolumn{4}{|l|}{ Prior Stroke* } \\
\hline No & $69841(84.9)$ & $53129(84.2)$ & $16712(87.3)$ \\
\hline Yes & $12378(15.1)$ & $9943(15.8)$ & $2435(12.7)$ \\
\hline \multicolumn{4}{|l|}{ Admission Year* } \\
\hline 2000 & $15060(18.3)$ & $11668(18.5)$ & $3392(17.7)$ \\
\hline 2001 & $15427(18.8)$ & $11796(18.7)$ & $3631(19.0)$ \\
\hline 2002 & $16438(20.0)$ & $12522(19.9)$ & $3916(20.5)$ \\
\hline
\end{tabular}




\begin{tabular}{|lccc|}
\hline 2003 & $17257(21.0)$ & $13248(21.0)$ & $4009(20.9)$ \\
2004 & $18037(21.9)$ & $13838(21.9)$ & $4199(23.3)$ \\
Hospital teaching status* & & & \\
General hospital & $19270(23.4)$ & $14747(23.4)$ & $4523(23.6)$ \\
Top clinical hospital & $55828(67.9)$ & $42767(67.8)$ & $13061(68.2)$ \\
Academic Medical Center & $7121(8.7)$ & $5558(8.8)$ & $1563(8.2)$ \\
Hospital location*ं & & & \\
Rural & $6763(8.2)$ & $5281(8.4)$ & $1482(7.7)$ \\
Urban 1 & $3019(3.7)$ & $2383(3.8)$ & $636(3.3)$ \\
Urban 2 & $11151(13.6)$ & $8679(13.8)$ & $2472(12.9)$ \\
Urban 3 & $36403(44.3)$ & $27677(43.9)$ & $8726(45.6)$ \\
Urban 4 & $24883(30.3)$ & $19052(30.2)$ & $5831(30.5)$ \\
Shift of admission & & & \\
Day $(8: 00$ AM $-3: 59$ PM) & $47205(57.4)$ & $37873(60.0)$ & $9332(48.7)$ \\
Evening $(4: 00$ PM - 11:59 PM) & $27410(33.3)$ & $19663(31.2)$ & $7747(40.5)$ \\
Night $(12: 00$ AM $-7: 59$ AM) & $7604(9.2)$ & $5536(8.8)$ & $2068(10.8)$ \\
Referrals & $21599(26.3)$ & $15977(74.0)$ & $5622(26.0)$ \\
\hline & $*$ Prvalue $<0.005$ & &
\end{tabular}

Table 2 displays the results of the association between weekend/weekday, day-of-admission, and shift-of-admission, and stroke case-fatality. Weekday admissions accounted for $76.7 \%$, the observed seven-day case-fatality was $7.3 \%$ on weekdays and $10.1 \%$ during the weekend. Compared to weekday admissions, weekend admissions were associated with an increased stroke case-fatality, with an unadjusted OR of 1.42 (95\% CI, $1.34-1.50)$ but an adjusted OR of 1.26 (95\% CI, $1.19-1.34)$.

In the association between day-of-admission and stroke case-fatality (Table 2), Monday accounted for the largest proportion of admissions, (18.0\%) while Saturday accounted for the smallest $(10.3 \%)$. The observed case-fatality is highest on Sunday and Saturday at $10.3 \%$ and $10.0 \%$ respectively. From Monday to Friday, the observed case-fatality ranged from $6.8 \%$ to $7.8 \%$. The unadjusted model showed an increase in the odds of stroke case-fatality on Sunday, Friday and Saturday. Despite further adjustments the odds of case-fatality remained high on Saturday (OR 1.20; $95 \%$ CI, $1.09-1.31$ ) and Sunday (OR 1.31; 95\% CI, $1.20-1.44)$.

Table 2 also displays the results of the categorization based on the shift-of-admission. The weekday day-shift accounted for the majority of admissions (51.4\%), while the observed case-fatality ranged from $6.4 \%$ to $10.9 \%$ over all shifts. The multivariate analysis for the shifts showed an increase in case-fatality odds for all other shifts when compared to the weekday day-shift in all models. In all 
categorizations the models excluding the attending physician were not significantly different from the final model. The inclusion of the covariates reduced the total variance by between $26-28 \%$. The ICC for all models was $1.8 \%$.

Table 2. Association between weekday/weekend, day, and shift of admission and stroke case-fatality

\begin{tabular}{|c|c|c|c|c|}
\hline Time of admission & $\begin{array}{c}\text { Number of } \\
\text { admissions } \\
(\%)\end{array}$ & $\begin{array}{c}\text { Observed } \\
\text { 7-day } \\
\text { case- } \\
\text { fatality } \\
(\%)\end{array}$ & Unadjusted OR & $\begin{array}{c}\text { Adjusted OR } \\
\text { (including attending } \\
\text { Physician) }\end{array}$ \\
\hline \multicolumn{5}{|c|}{ Weekend/Weekday admission } \\
\hline Weekday & $63072(76.7)$ & 7.3 & Reference & Reference \\
\hline Weekend & $19147(23.3)$ & 10.1 & $1.42(1.34-1.50)^{*}$ & $1.27(1.20-1.34)^{*}$ \\
\hline PCV & - & - & Ref & $-26 \%$ \\
\hline ICC & - & - & 0.024 & 0.018 \\
\hline \multicolumn{5}{|l|}{ Day of admission } \\
\hline Sunday & $9283(11.2)$ & 10.3 & $1.47(1.34-1.61)^{*}$ & $1.31(1.20-1.44)^{*}$ \\
\hline Monday & $14835(18.0)$ & 7.1 & Reference & Reference \\
\hline Tuesday & $13181(16.0)$ & 7.3 & $1.01(0.92-1.10)$ & $1.01(0.92-1.11)$ \\
\hline Wednesday & $12693(15.4)$ & 6.8 & $0.95(0.87-1.04)$ & $0.94(0.83-1.03)$ \\
\hline Thursday & $12360(15.0)$ & 7.6 & $1.05(0.96-1.15)$ & $1.02(0.93-1.12)$ \\
\hline Friday & $11360(13.8)$ & 7.8 & $1.09(1.00-1.20)$ & $0.99(0.90-1.08)$ \\
\hline Saturday & $8507(10.3)$ & 10.0 & $1.42(1.29-1.56)^{*}$ & $1.20(1.09-1.31)^{*}$ \\
\hline PCV & - & - & Ref & $-26 \%$ \\
\hline ICC & - & - & 0.025 & 0.018 \\
\hline \multicolumn{5}{|l|}{ Shift of admission } \\
\hline Weekday day & $42240(51.4)$ & 6.4 & Reference & Reference \\
\hline Weekday evening & $13873(16.9)$ & 8.3 & $1.31(1.22-1.41)^{*}$ & $1.09(1.01-1.17)^{*}$ \\
\hline Weekday night & $6959(8.4)$ & 10.3 & $1.71(1.57-1.87)^{*}$ & $1.71(1.56-1.87)^{*}$ \\
\hline Weekend day & $13645(16.6)$ & 9.7 & $1.56(1.45-1.67)^{*}$ & $1.33(1.24-1.43)^{*}$ \\
\hline Weekend night & $5502(6.7)$ & 10.9 & $1.77(1.61-1.94)^{*}$ & $1.54(1.40-1.70)^{*}$ \\
\hline PCV & - & - & Ref & $-28 \%$ \\
\hline ICC & - & - & 0.025 & 0.018 \\
\hline
\end{tabular}

Figure 1 shows the adjusted association between the day-and-shift-of-admission and stroke case-fatality. The overall pattern is one of increased case-fatality odds during the evening- and nightshifts, and the day-shifts of Saturday and Sunday. The results of the analysis using three eight-hour shifts per day did not differ significantly from this (see table A11)

Figure 2 shows the adjusted association between hour-of-admission and stroke case-fatality after adjusting for all covariates including attending physician and weekend admissions. Compared to those admitted at 8:00 AM, patients admitted from midnight until 7:00 AM had higher odds of dying 
within 7 days. During the hours of 2:00 PM, 3:00 PM, 4:00 PM and 5:00 PM the case-fatality odds were reduced: OR 0.82 (95\% CI 0.67 - 1.00), OR 0.75 (95\% CI 0.62 - 0.92), OR 0.74 (95\% CI 0.61 $0.91)$, and OR $0.74(0.60-0.91)$ respectively. This pattern persisted in all models including that with the day of admission variable (See online appendix table A14).

Table 3 shows the influence of hour-of-admission on fatality, stratified by weekends and weekdays. There were persistently higher case-fatality odds during the nighttime hours and the protective effect for weekday admissions only.

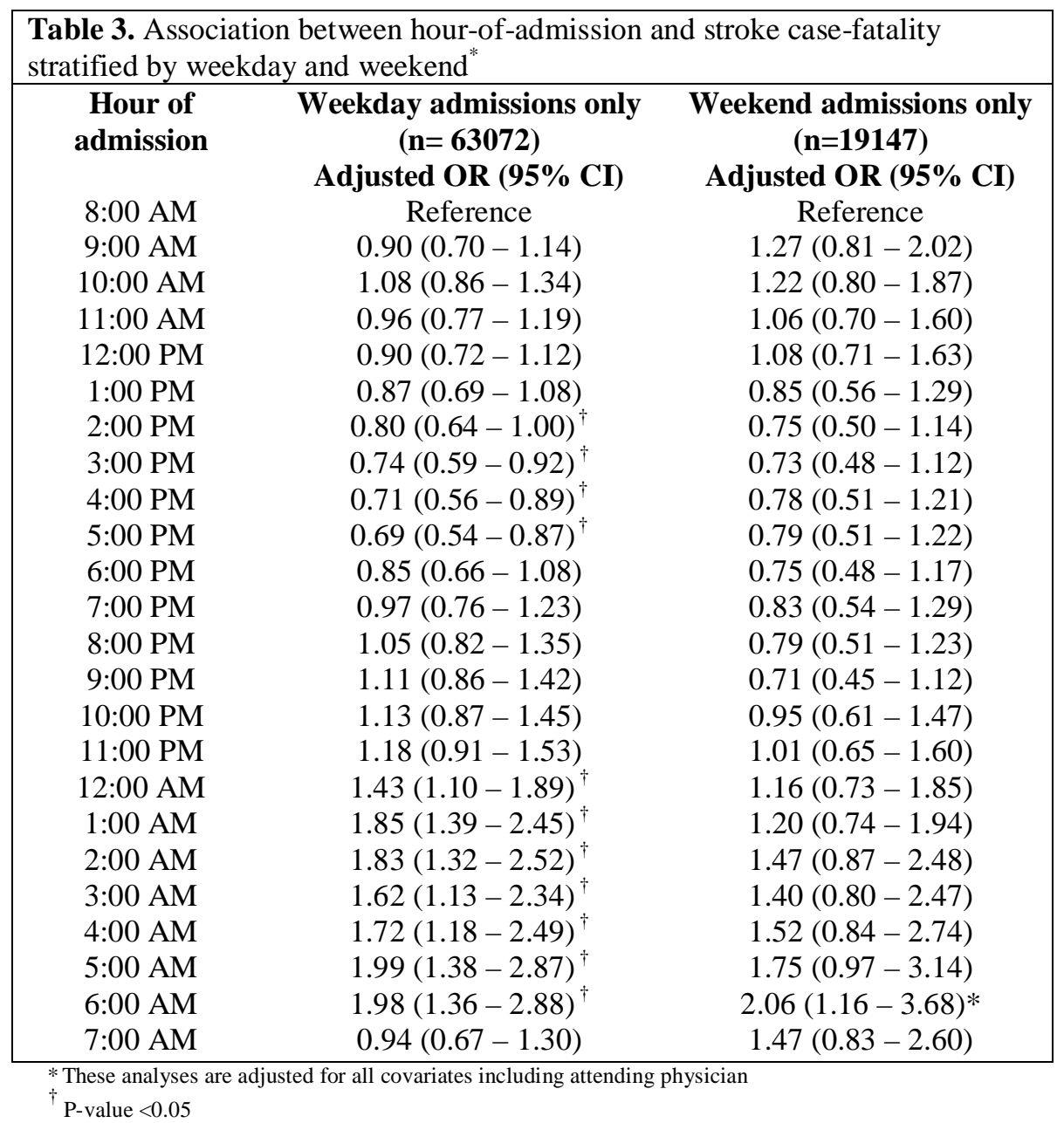

Sensitivity analysis, including 60,620 admissions, showed results were not materially altered by the exclusion of referred patients (Appendix Tables A1 - A7). The appendix (Tables A8 - A14) also displays the complete results for all models in the main analysis. 


\section{DISCUSSION}

Using progressively more refined definitions of time of admission, this study demonstrates not only the presence of a harmful weekend effect but also a stronger nighttime effect, and a protective effect for admissions from 3:00 PM to 6:00 PM on weekdays in a cohort of ischemic stroke patients in the Netherlands. The observed nighttime effect presented itself as higher seven-day case-fatality odds during the night-shifts and among patients admitted from midnight until 7:00 AM.

This study has a number of strengths and limitations; the study sample was based on admission to most Dutch hospitals thus providing a unique snapshot of ischemic stroke patients in the Dutch health system. Variations in the quality of care between on- and off-hours have been identified as a potential explanation for the identified weekend effect.[26] Specific clinical data on treatments received were unavailable in this administrative database, however the quality of care received by stroke patients in the Netherlands receives high marks.[27;28] The six-month case-fatality rate in the Netherlands compared favorable to those in the United Kingdom, Australia, Italy, Sweden and Norway.[29] In 2005, thirty-day mortality rate among Dutch stoke patients (9.2\%) was below the Organization for Economic Cooperation and Development (OECD) average (10.2\%).[30] Data on specific stroke units was unavailable however in 2002 the majority of Dutch hospitals has stoke units or were affiliated with a stroke service.[31] The administrative nature of the database restricted the amount of clinical information available on severity for use in case-mix adjustment. Nonetheless, we used numerous variables such as the perceived urgency of the admission, prior stroke, and the Charlson-Deyo index to mitigate this drawback. The relatively short-term outcome makes length of stay an unlikely predictor of mortality, this has been observed in an analysis of hospital volumemortality association [32]. The inclusion of all categories of hospitals in rural and urban locations and the specialty of the physician in charge of the case was advantageous for statistical adjustments. By using various definitions, we shed more light on the complex association between time of admission and case-fatality. 
The results of the classification of time of admission as weekdays and weekends and by day of admission agreed with those studies that have demonstrated increased fatality for weekend admissions and for Saturday and Sunday admissions. A superficial look at the shift-of-admission showed increased odds of fatality during all shifts compared to the weekday day-shift. A deeper look at the day-and-shift-of-admission showed a common pattern of increased nighttime fatality odds on all days that extended to the other shifts on Saturday and Sunday. The hour-of-admission categorization provided an interesting pattern of increased case-fatality from midnight until 7:00AM. It also revealed a protective effect from 3:00 PM until 6:00 PM that persisted when analysis was restricted to weekday admissions. This latter period coincided with the handover period when the day-shift ended and the evening-shift began.

Studies attribute the observed higher case-fatality risk among off-hours admission in part due to the expectation of more severe patients presenting at these times. Although our study cannot firmly dispute such conclusions, a study of stroke patients showed no difference in clinical features between patients admitted during the on- and off-hours.[33] In our data, a larger proportion of admissions designated urgent occurred during the weekend. This designation of urgent represents an assessment on admission of the severity of admission. Non-urgent admissions represent those who made appointments or presented and were deemed non-emergencies. Thus they could be slowly developing or mild strokes. We adjusted for this and other factors, and still observed an increase in the casefatality odds for nighttime and weekend admissions. On its own, the urgency of admission was highly predictive of the case-fatality odds (see online appendix). The ICC indicates that only $1.8 \%$ of the total variation is attributed to differences between hospitals included in this study.

Quality of care is said to be reduced during the off-hours. Studies have highlighted decreased adherence to guidelines, reduced to investigations and procedures, less experienced, and fewer staff members available to patients during the off-hours. In our study, the specialty of the physician in charge of the case did seem systematically related to off-hours care. The specialty and experience of the point of first contact might be a more influential factor. The lower fatality risk observed among 
patients admitted the handover period could represent the benefits of temporary increase in staff numbers and greater attention to detail that would occur during the period.

An important finding is that we observe what appears to be a baseline nighttime risk. A possible explanatory factor not commonly addressed is human nature. The human circadian rhythm is such that cognitive performance varies throughout the day.[34] At night in the absence of light, cognitive performance suffers[34] leading to increased medical errors.[35] Studies of shift workers have shown that prolonged exposure to altered work patterns yielded some degree of adaptation.[36] However, the relatively short and irregular nature of night shifts in hospitals makes this less likely to occur. It also does not take into account the different chronotypes, as some individuals can adapt better to the alternating conditions than others can.[37] The adjustment of total resident working hours has reduced daytime fatigue and medical errors, but little attention is paid to the natural fatigue experienced during a night shift.[38-40]

This study moves beyond the classical weekend/weekday classification, we demonstrated what appears to be the presence of a baseline nighttime risk exacerbated during the weekend. The protective effect during the handover period would seem to reinforce that the number of staff available matters. Our study points to the need for further analysis of the influence of the effects of nighttime work on medical staff and patients, and an approach to labor planning in hospitals that goes beyond patient-to-provider ratios and total on-/off-hours.

\section{ACKNOWLEDGMENTS AND FUNDING}

This project was funded by grant S/260116-2007 from the Dutch National Institute of Public Health and the Environment (RIVM). The funders had no role in study design, data collection, data analysis, data interpretation, or writing of the report. Dr. Arah is supported by a grant (Veni number 916.96.059) from the Netherlands Organization for Scientific Research (NWO).

The authors declare that they have no conflicts of interests. the Corresponding Author has the right to grant on behalf of all authors and does grant on behalf of all authors, an exclusive licence (or non exclusive for government employees) on a worldwide basis to the BMJ Publishing Group Ltd and its 
Licensees to permit this article (if accepted) to be published in the Journal of Neurology,

Neurosurgery \& Psychiatry editions and any other BMJPGL products to exploit all subsidiary rights, as set out in our licence (http://jnnp .bmjjournals.com/ifora/licence.pdf). 
References

1. Barba R, Losa JE, Velasco M et al. Mortality among adult patients admitted to the hospital on weekends. Eur J Intern Med 2006;17:322-4.

2. Reeves MJ, Smith E, Fonarow G et al. Off-hour admission and in-hospital stroke case fatality in the get with the guidelines-stroke program. Stroke 2009;40:569-76.

3. Cram P, Hillis SL, Barnett M et al. Effects of weekend admission and hospital teaching status on in-hospital mortality. Am J Med 2004;117:151-7.

4. Hasegawa Y, Yoneda Y, Okuda S et al. The effect of weekends and holidays on stroke outcome in acute stroke units. Cerebrovasc Dis 2005;20:325-31.

5. Kostis WJ, Demissie K, Marcella SW et al. Weekend versus weekday admission and mortality from myocardial infarction. N Engl J Med 2007;356:1099-109.

6. Peberdy MA, Ornato JP, Larkin GL et al. Survival from in-hospital cardiac arrest during nights and weekends. JAMA 2008;299:785-92.

7. Redelmeier DA, Bell CM. Weekend worriers. N Engl J Med 2007;356:1164-5.

8. Saposnik G, Baibergenova A, Bayer N et al. Weekends: a dangerous time for having a stroke? Stroke 2007;38:1211-5.

9. Shaheen AA, Kaplan GG, Myers RP. Weekend versus weekday admission and mortality from gastrointestinal hemorrhage caused by peptic ulcer disease. Clin Gastroenterol Hepatol 2009;7:303-10.

10. Zare MM, Itani KM, Schifftner TL et al. Mortality after nonemergent major surgery performed on Friday versus Monday through Wednesday. Ann Surg 2007;246:866-74. 
11. Shulkin DJ. Like night and day--shedding light on off-hours care. $N$ Engl J Med 2008;358:2091-3.

12. Bendavid E, Kaganova $Y$, Needleman $\mathrm{J}$ et al. Complication rates on weekends and weekdays in US hospitals. Am J Med 2007;120:422-8.

13. Magid DJ, Wang Y, Herrin J et al. Relationship between time of day, day of week, timeliness of reperfusion, and in-hospital mortality for patients with acute ST-segment elevation myocardial infarction. JAMA 2005;294:803-12.

14. Aujesky D, Jimenez D, Mor MK et al. Weekend versus weekday admission and mortality after acute pulmonary embolism. Circulation 2009;119:962-8.

15. Foss NB, Kehlet H. Short-term mortality in hip fracture patients admitted during weekends and holidays. Br J Anaesth 2006;96:450-4.

16. Schmulewitz L, Proudfoot A, Bell D. The impact of weekends on outcome for emergency patients. Clin Med 2005;5:621-5.

17. Luyt CE, Combes A, Aegerter P et al. Mortality among patients admitted to intensive care units during weekday day shifts compared with "off" hours. Crit Care Med 2007;35:3-11.

18. Albright KC, Raman R, Ernstrom K et al. Can comprehensive stroke centers erase the 'weekend effect'? Cerebrovasc Dis 2009;27:107-13.

19. de Bruin A, de Bruin EI, Gast A et al. Koppeling van LMR-en GBA gegevens: methode, resultanten en kwaliteitsonderzoek. Voorburg/Heerleen: Statistics Netherlands, 2003.

20. de Bruin A, Karduan J, Gast F et al. Record Linkage of hospital discharge register with population register: Experiences at Statistics Netherlands. Journal of the United Nations ECE $2004 ; 21: 23-32$. 
21. Kokotailo RA, Hill MD. Coding of stroke and stroke risk factors using international classification of diseases, revisions 9 and 10. Stroke 2005;36:1776-81.

22. Stronks K, Kulu-Glasgow I, Agyemang C. The utility of 'country of birth' for the classification of ethnic groups in health research: the Dutch experience. Ethn Health 2008;14:1-14.

23. Agyemang C, Vaartjes I, Bots ML et al. Risk of death after first admission for cardiovascular diseases by country of birth in The Netherlands: a nationwide record-linked retrospective cohort study. Heart 2009;95:747-53.

24. Heijink R, Koolman X, Pieter D et al. Measuring and explaining mortality in Dutch hospitals; the hospital standardized mortality rate between 2003 and 2005. BMC Health Serv Res 2008;8:73.

25. Jauss $\mathrm{M}$, Oertel $\mathrm{W}$, Allendoerfer $\mathrm{J}$ et al. Bias in request for medical care and impact on outcome during office and non-office hours in stroke patients. Eur J Neurol. 2009;16:1165-7

26. Goldstein LB, Samsa GP, Matchar DB, Horner RD. Charlson Index comorbidity adjustment for ischemic stroke outcome studies. Stroke 2004;35:1941-5.

27. Minkman MM, Schouten LM, Huijsman R et al. Integrated care for patients with a stroke in the Netherlands: results and experiences from a national Breakthrough Collaborative Improvement project. Int J Integr Care 2005;5:e14.

28. Scholte Op Reimer WJ, Dippel DW, Franke CL et al. Quality of hospital and outpatient care after stroke or transient ischemic attack: insights from a stroke survey in the Netherlands. Stroke 2006;37:1844-9.

29. Weir NU, Sandercock PA, Lewis SC et al. Variations between countries in outcome after stroke in the International Stroke Trial (IST). Stroke 2001;32:1370-7. 
30. Westert GP, Berg MJ van den, Koolman X, Verkleij H, (Eds). Dutch Health Care Performance Report 2008. Bilthoven: National Institute for Public Health and the Environment, 2008:109111.

31. Evers SMAA, Struijs JN, Ament AJHA et al. The disease impact, healthcare management and cost of stroke in the Netherlands. Bilthoven: National Institute for Public Health and the Environment. 2002

32. Ogbu UC et, Slobbe LCJ al, Arah OA. Hospital stroke volume and case-fatality revisited. Med Care 2010;48:149-56

33. Bassetti C, Aldrich M. Night time versus daytime transient ischaemic attack and ischaemic stroke: a prospective study of 110 patients. J Neurol Neurosurg Psychiatry 1999;67:463-7.

34. Blatter K, Cajochen C. Circadian rhythms in cognitive performance: methodological constraints, protocols, theoretical underpinnings. Physiol Behav 2007;90:196-208.

35. Dorrian J, Tolley C, Lamond $\mathrm{N}$ et al. Sleep and errors in a group of Australian hospital nurses at work and during the commute. Appl Ergon 2008;39:605-13.

36. Costa G. Shift work and occupational medicine: an overview. Occup Med (Lond) 2003;53:83-8.

37. Roenneberg T, Kuehnle T, Juda M et al. Epidemiology of the human circadian clock. Sleep Med Rev 2007;11:429-38.

38. Iglehart JK. Revisiting duty-hour limits--IOM recommendations for patient safety and resident education. $N$ Engl J Med 2008;359:2633-5.

39. Shetty KD, Bhattacharya J. Changes in hospital mortality associated with residency work-hour regulations. Ann Intern Med 2007;147:73-80.

40. Volpp KG, Landrigan CP. Building physician work hour regulations from first principles and best evidence. JAMA 2008;300:1197-9. 


\begin{tabular}{|c|c|c|c|c|}
\hline $\begin{array}{l}\text { Day and "regular" shift } \\
\text { of admission }\end{array}$ & $\begin{array}{l}\text { Number of } \\
\text { admissions }\end{array}$ & $\begin{array}{c}\text { Observed 7-day } \\
\text { case-fatality } \\
\text { n (\%) }\end{array}$ & $\begin{array}{l}\text { Adjusted OR } \\
\text { (including attending } \\
\text { Physician) }\end{array}$ & \\
\hline Sunday day-shift & 6652 & $666(10.0)$ & $1.44(1.28-1.62)^{*}$ & $\therefore \rightarrow$ \\
\hline Sunday night-shift & 2631 & $288(10.9)$ & $1.61(1.38-1.88)^{*}$ & $: \rightarrow$ \\
\hline Monday day-shift & 9540 & $575(6.0)$ & 1.00 & $\dot{0}$ \\
\hline Monday evening-shift & 3091 & $260(8.4)$ & $1.16(0.99-1.35)$ & $\rightarrow$ \\
\hline Monday night-shift & 1659 & $170(10.2)$ & $1.86(1.55-2.24)^{*}$ & $: \rightarrow$ \\
\hline Tuesday day-shift & 9010 & $567(6.3)$ & $1.03(0.91-1.17)$ & $\rightarrow$ \\
\hline Tuesday evening-shift & 2678 & $228(8.5)$ & $1.13(0.96-1.33)$ & io \\
\hline Tuesday night-shift & 1362 & $143(10.5)$ & $1.76(1.44-2.14)^{*}$ & $: \rightarrow$ \\
\hline Wednesday day-shift & 8489 & $501(5.9)$ & $0.95(0.83-1.07)$ & $\dot{\theta}$ \\
\hline Wednesday evening-shift & 2721 & $220(8.1)$ & $1.09(0.92-1.29)$ & $+0-$ \\
\hline Wednesday night-shift & 1352 & $137(10.1)$ & $1.78(1.45-2.17)^{*}$ & $\therefore \quad \rightarrow$ \\
\hline Thursday day-shift & 8062 & $554(6.9)$ & $1.09(0.97-1.23)$ & in \\
\hline Thursday evening-shift & 2717 & $220(8.1)$ & $1.08(0.91-1.27)$ & $\rightarrow$ \\
\hline Thursday night-shift & 1328 & $137(10.3)$ & $1.66(1.36-2.03)^{*}$ & $: \rightarrow$ \\
\hline Friday day-shift & 7139 & $515(7.2)$ & $1.03(0.92-1.18)$ & $\theta$ \\
\hline Friday evening-shift & 2666 & $223(8.4)$ & $1.09(0.93-1.29)$ & $+\infty$ \\
\hline Friday night-shift & 1258 & $128(10.2)$ & $1.64(1.33-2.02)^{*}$ & $: \rightarrow$ \\
\hline Saturday day-shift & 6014 & $588(9.8)$ & $1.30(1.15-1.47)^{*}$ & $\therefore \rightarrow$ \\
\hline Saturday night-shift & 2493 & $264(10.6)$ & $1.49(1.28-1.75)^{*}$ & $\rightarrow$ \\
\hline Holiday day-shift & 979 & $76(7.8)$ & $1.13(0.88-1.46)^{*}$ & مبن \\
\hline Holiday night-shift & 378 & $47(12.4)$ & $1.88(1.36-2.60)^{*}$ & \\
\hline
\end{tabular}

Dotted vertical line represents an odds ratio of 1

o Represents Odds Ratio; Error bars represent 95\% Confidence Interval

${ }^{a}$ White circles indicate day-shifts, Blue circles indicate evening-shifts, Black circles indicate night-shift

Red borders indicate weekends 


\begin{tabular}{|c|c|c|c|c|}
\hline $\begin{array}{c}\text { Hour of } \\
\text { admission }\end{array}$ & $\begin{array}{l}\text { Number of } \\
\text { admissions }\end{array}$ & $\begin{array}{c}\text { Observed 7-day } \\
\text { case-fatality } \\
\text { n (\%) }\end{array}$ & $\begin{array}{c}\text { Adjusted OR } \\
\text { (including attending } \\
\text { physician and weekend } \\
\text { variable) }\end{array}$ & ; \\
\hline $11: 00 \mathrm{PM}$ & 2122 & $226(10.7)$ & $1.14(0.92-1.43)$ & to \\
\hline $12: 00 \mathrm{AM}$ & 1720 & $198(11.5)$ & $1.38(1.10-1.74)^{*}$ & ' \\
\hline $1: 00 \mathrm{AM}$ & 1223 & $165(13.5)$ & $1.63(1.28-2.07)^{*}$ & ; \\
\hline 2:00 AM & 771 & $109(14.1)$ & $1.73(1.32-2.27)^{*}$ & ; \\
\hline $3: 00 \mathrm{AM}$ & 576 & $75(13.0)$ & $1.57(1.16-2.13)^{*}$ & \\
\hline $4: 00 \mathrm{AM}$ & 533 & $69(12.9)$ & $1.69(1.24-2.31)^{*}$ & \\
\hline 5:00 AM & 481 & $74(15.4)$ & $1.96(1.44-2.67)^{*}$ & ; \\
\hline $6: 00 \mathrm{AM}$ & 477 & $73(15.3)$ & $2.05(1.50-2.79)^{*}$ & ; \\
\hline 7:00 AM & 1823 & $83(4.6)$ & $1.04(0.79-1.39)$ & - \\
\hline $8: 00 \mathrm{AM}$ & 3416 & $156(4.6)$ & 1.00 & 0 \\
\hline 9:00 AM & 4522 & $248(5.5)$ & $0.98(0.79-1.21)$ & $\theta$ \\
\hline $10: 00 \mathrm{AM}$ & 6043 & $460(7.6)$ & $1.13(0.93-1.37)$ & in \\
\hline $11: 00 \mathrm{AM}$ & 7556 & $548(7.3)$ & $1.00(0.83-1.22)$ & $\dot{\theta}$ \\
\hline $12: 00 \mathrm{PM}$ & 6097 & $524(8.6)$ & $0.97(0.80-1.18)$ & 4 \\
\hline $1: 00 \mathrm{PM}$ & 6411 & $499(7.8)$ & $0.88(0.72-1.07)$ & $\theta$ \\
\hline 2:00 PM & 6914 & $503(7.3)$ & $0.81(0.67-0.99)^{*}$ & 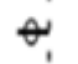 \\
\hline $3: 00 \mathrm{PM}$ & 6246 & $440(7.0)$ & $0.76(0.62-0.92)^{*}$ & $\theta$ \\
\hline $4: 00 \mathrm{PM}$ & 5548 & $389(7.0)$ & $0.74(0.61-0.91)^{*}$ & $\theta$ \\
\hline $5: 00 \mathrm{PM}$ & 4417 & $310(7.0)$ & $0.73(0.59-0.90)^{*}$ & $\theta^{\prime}$ \\
\hline $6: 00 \mathrm{PM}$ & 3666 & $292(8.0)$ & $0.84(0.68-1.03)$ & $\theta$ \\
\hline 7:00 PM & 3314 & $294(8.9)$ & $0.94(0.76-1.16)$ & $\theta$ \\
\hline $8: 00 \mathrm{PM}$ & 2966 & $258(8.7)$ & $0.99(0.80-1.23)$ & - \\
\hline 9:00 PM & 2793 & $256(9.2)$ & $0.99(0.79-1.22)$ & $\rightarrow$ \\
\hline $10: 00$ PM & 2584 & $260(10.1)$ & $1.09(0.87-1.35)$ & $\Rightarrow$ \\
\hline
\end{tabular}

